\title{
Cutaneous abacterial inflammatory reaction in patients with ulcerative colitis
}

\author{
PER WOLF-JÜRGENSEN, POUL ANTHONISEN, AND POVL RIIS \\ From Glostrup Hospital, Medical Department B, and Gentofte Hospital, \\ Medical Department B, Denmark
}

EDITORIAL SYNOPSIS It has been previously suggested that patients with ulcerative colitis might have an atypical inflammatory response, indicating a new type of hyposensitivity. This hypothesis has not been confirmed in this study.

Using their 'skin window' technique Priest, Rebuck, and Havey (1960), Rebuck, Petz, Riddle, Priest, and LoGrippo (1961), and Rebuck, Hodson, Priest, and Barth (1963) found that the cutaneous abacterial inflammation in patients with ulcerative colitis showed an atypical pattern of leucocyte response which, in 26 of the 41 patients studied, included the migration of relatively large numbers of basophilic granulocytes. Rebuck and his colleagues construed this inflammatory reaction as an indication of a qualitative defect of leucocyte function in patients with ulcerative colitis, and suggested that the response represented a new type of hypersensitivity reaction. The present study was undertaken to test their conclusions.

\section{PRESENT INVESTIGATION}

METHODS The technique employed was on all essential points similar to that of Rebuck et al. (1961): after excoriation of a suitable area of the skin on the volar side of the forearm $0.1 \mathrm{ml}$. of diphtheria toxoid was injected into the dermis directly under the lesion.

This technique has proved capable of producing classical delayed hypersensitivity reactions (WolfJürgensen, 1965); Rebuck et al. (1961) applied diphtheria toxoid to the surface of the lesion.

The first 'skin window' was put in place immediately hereafter and the inflammation was followed for 48 hours, the 'windows' being changed at approximately threehour intervals. An inflammation on the patient's other forearm produced in a similar manner, but with the use of inactivated diphtheria toxoid, served as control. In four of the patients with ulcerative colitis $0.1 \mathrm{ml}$. of saline was employed in the control inflammation instead of inactivated diphtheria toxoid. In all the experiments sterile conditions were, of course, maintained.

In all the patients with ulcerative colitis a cytological examination of the colonic mucosal secretions was carried out using the replica method described in a previous communication (Anthonisen and Riis, 1961).

MATERIAL The ulcerative colitis material comprised four women aged 18 to 52 years (average 34.5 years) and seven men aged 18 to 70 years (average 34.0 years). One patient was examined in the post-operative period after acute colectomy (the replica method being employed on the rectal stump); the rest of the patients were all in an active phase of the disease. In three patients the mucosal inflammation had a chiefly distal localization ('haemorrhagic proctitis'); in the remaining cases, including the patient on whom colectomy had been performed, the inflammatory process involved the whole or greater part of the colon. Nine of the patients were not given corticosteroid treatment at the time of this investigation; one was treated with cortisol enemas, and one received cortisol enemas as well as general therapy with prednisone and corticotrophin.

The control material consisted of 13 patients with diseases of no relevance in this connexion, mainly of a surgical nature. Five were women aged 16 to 40 years (average 24.4 years) and eight were men aged 18 to 55 years (average $31 \cdot 1$ years).

None of the patients in the present study had interstitial cystitis (Hunner's ulcer) or regional enteritis, in which conditions Rebuck et al. (1963) have also found cutaneous inflammatory basophilia.

The Schick test was carried out on all the patients before or simultaneously with the start of the 'skin window' experiments. Seven patients with ulcerative colitis and eight control patients were Schick-negative; the remaining patients were Schick-positive.

\section{RESULTS}

From Table $I$ it appears that the cutaneous inflammatory reaction to a mechanical stimulus plus diphtheria toxoid was characterized by basophilia in four patients with ulcerative colitis and in eight 
TABLE I

PRESENCE OF BASOPHILS IN 'SKIN-WINDOWS' FROM PATIENTS WITH ULCERATIVE COLITIS AND CONTROLS

Group

Number of Patients with Local Basophilia

Toxoid Saline or Control Solution

\begin{tabular}{llll}
\hline Ulcerative colitis (11) & $\begin{array}{c}\text { Schick-positive } \\
(4)\end{array}$ & 0 & 0 \\
Schick-negative & 4 & 0 \\
Control patients (13) & $\begin{array}{c}\text { Schick-positive } \\
(5)\end{array}$ & 0 & 0 \\
Schick-negative & 8 & 2
\end{tabular}

(8)

control patients. (Basophilia was registered if the basophil count in the 'skin window' rose to $2 \%$ or more during the experiment.) Typical basophilia is shown in Figure 1.

Of the seven Schick-negative ulcerative colitis patients four showed cutaneous basophilia; one of these was on intensive corticosteroid treatment. Of

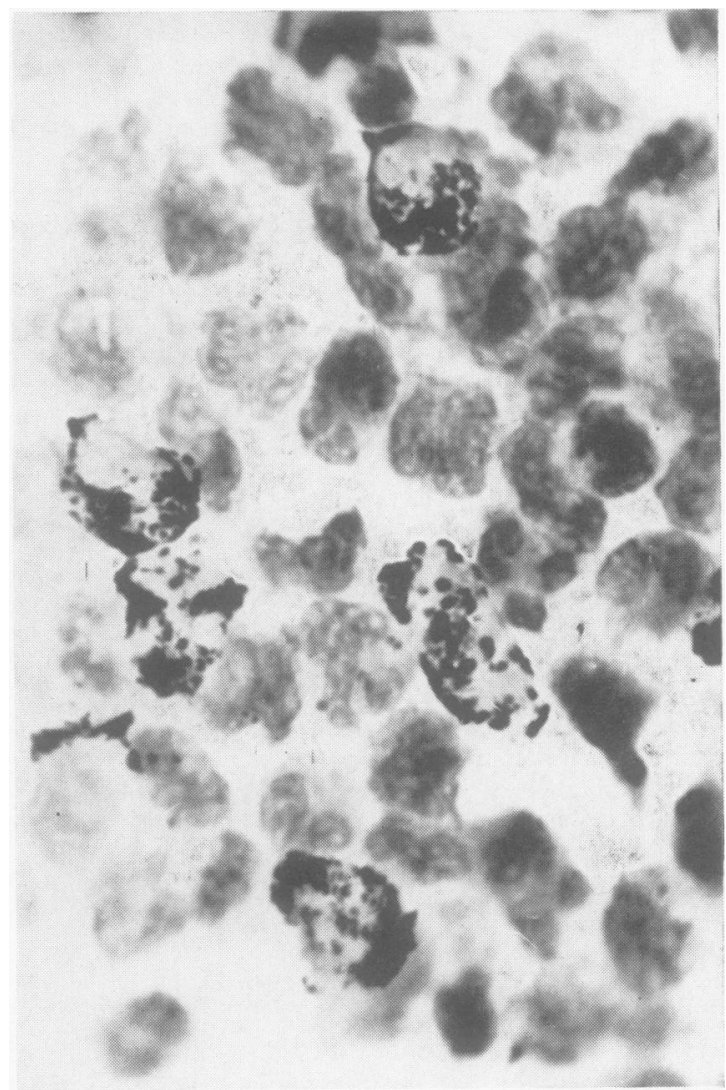

FIG. 1. Example of inflammatory basophilia in a 'skin window'. May-Grunwald-Giemsa. (Approx. $\times$ 1,000). the eight Schick-negative control patients all had cutaneous basophilia. That none of the Schickpositive patients, neither in the ulcerative colitis material nor in the control group, showed cutaneous basophilia is probably quite fortuitous.

In two control patients the basophil counts rose to 2 and $2.5 \%$ respectively in 'skin windows' from the control inflammations, where inactivated diphtheria toxoid was employed, so that slight basophilia was registered. Both these patients were Schicknegative. In none of the remaining control patients or patients with ulcerative colitis, including the four to whom saline was applied, was basophilia encountered in the control inflammations.

Figure 2 shows a typical example of the development of cutaneous basophilia in a patient with ulcerative colitis and in a control patient.

Using the replica method mentioned above it has been shown (Riis and Anthonisen, 1964) that the inflammatory exudate from the colonic mucosa of patients with ulcerative colitis as a rule is characterized by distinct eosinophilia. In very few cases

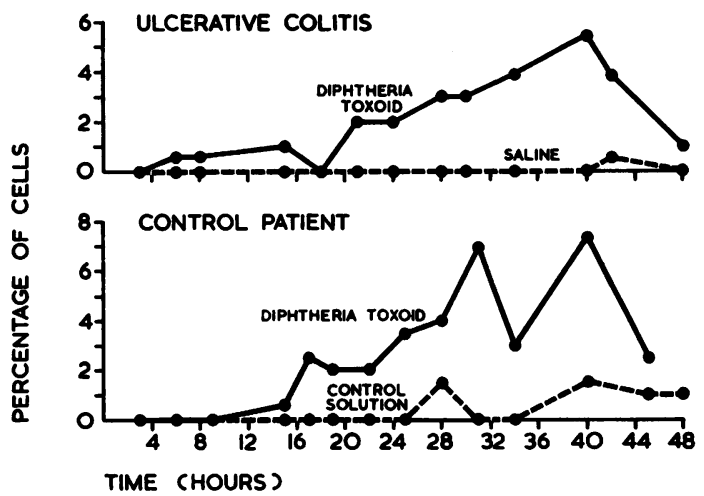

FIG. 2. Typical development of 'skin window' basophilia in a patient with ulcerative colitis and in a control patient.

basophilic granulocytes have been observed. Cytological examination of the colonic mucosal secretions did not disclose basophilia in any of the ulcerative colitis patients included in the present study.

\section{DISCUSSION}

Rebuck et al. (1963) in their series of patients with ulcerative colitis found an atypical cutaneous inflammatory response which in more than half the patients included excessive migration of basophilic granulocytes. A similar atypical response was observed in patients with regional enteritis and with interstitialcystitis(Hunner's ulcer). Cutaneous inflammatory basophilia was found in Schick-positive as 
well as in Schick-negative patients. In contrast, the cutaneous inflammations in control subjects showed only a few occasional basophils. Rebuck et al. (1963) concluded that the atypical inflammatory response observed reflected a new type of hypersensitivity reaction characteristic of the diseases ulcerative colitis, regional enteritis, and interstitial cystitis.

The 'skin window' technique employed by Rebuck et al. (1961) included the application of diphtheria toxoid to the skin lesions of all the patients with ulcerative colitis, regional enteritis, and interstitial cystitis. In the control series, however, one of several antigens (egg white, diphtheria toxoid, triple typhoid vaccine, old tuberculin, and a non-viable Escherichia coli antigen) was applied to the lesions in individuals who were "known to be not systemically immunized by the respective antigens' (Rebuck et al., 1961).

In the present study cutaneous inflammatory basophilia was observed both in patients with ulcerative colitis and in control patients. The common feature in all the patients who showed this response was that they were Schick-negative. The 'skin window' technique used by us included the application of diphtheria toxoid to the lesions of the patients with ulcerative colitis as well of to those of the control patients.

$\mathrm{Hu}$, Fosnaugh, and Livingood (1963), in their paper on the cutaneous inflammatory response to staphylococcus in patients with cutaneous bacterial infections, stated as their experience that with diphtheria toxoid in 'skin windows' an increase of basophils and/or eosinophils occurred in a much higher percentage of individuals with a positive Moloney skin test, which indicates the presence of hypersensitivity to diphtheria toxoid. No absolute correlation with the Schick test was observed.

Pappenheimer and Lawrence (1948) found that both highly purified diphtheria toxoid and a mixture of atoxic diphtherial proteins could give rise to delayed reactions of the tuberculin type ('delayed hypersensitivity', independent of circulating antibodies) when injected subcutaneously in a series of normal subjects most of whom had probably been vaccinated against diphtheria. Delayed reactions were seen in Schick-positive as well as in Schicknegative subjects. (The Schick test is a measure only of the level of circulating diphtheria antitoxin, so that a positive result does not exclude the presence of delayed hypersensitivity to diphtheria toxoid or to atoxic diphtherial proteins.) The same authors (Lawrence and Pappenheimer, 1956) later showed that delayed hypersensitivity to diphtheria toxoid can be transferred by leucocyte extracts to nonsensitized subjects.

It has been shown (Wolf-Jürgensen, 1962) that inflammatory basophilia is characteristic of delayed hypersensitivity as seen in experimental skin contact allergy.

A reasonable conclusion to the facts listed above seems to be that the cutaneous inflammatory basophilia found by Rebuck et al. (1963) in patients with ulcerative colitis, regional enteritis, and interstitial cystitis, and by us in patients with ulcerative colitis as well as in control patients is not an expression of a new type of hypersensitivity but simply represents a hypersensitivity reaction of the delayed type to diphtheria toxoid or to non-toxic diphtherial proteins. The conclusion is favoured by Juhlin's (1963) finding that cantharidin-produced skin blisters in patients with ulcerative colitis did not contain abnormally great numbers of basophilic granulocytes.

The above conclusion does not, of course, affect the proposal of Rebuck et al. (1963) that tissue mast cells play an important pathogenic part in the local inflammatory process of ulcerative colitis. This conception is supported by the fact that proportionately large numbers of mast cells have been found in the walls of the colon of patients with the disease (McGovern and Archer, 1957; McAuley and Sommers, 1961).

\section{SUMMARY}

Rebuck et al. (1963) found numerous basophilic granulocytes in 'skin windows' from 26 out of 41 patients with ulcerative colitis, Schick-positive as well as Schick-negative, and construed this atypical inflammatory response as an indication of a new type of hypersensitivity reaction characteristic of this disease. The technique of these authors included the application of diphtheria toxoid to the skin lesions of all patients with ulcerative colitis, whereas in the control series diphtheria toxoid was only applied to the skin wounds of individuals known to be not sensitized to this antigen.

In the present study a similar 'skin window' technique was employed, including the application of diphtheria toxoid, in 11 patients with ulcerative colitis and in 13 patients with other diseases. Cutaneous inflammatory basophilia was observed in 12 Schick-negative patients, four with ulcerative colitis and eight from the control group. No Schickpositive patient in either group showed this atypical inflammatory response.

Pappenheimer and Lawrence (1948) observed many delayed reactions of the tuberculin type to both purified diphtheria toxoid and atoxic diphtherial proteins injected intracutaneously in a series of normal subjects most of whom had probably been vaccinated against diphtheria. Delayed hyper- 
sensitivity was seen in Schick-positive as well as in Schick-negative subjects.

Wolf-Jürgensen (1962) found inflammatory basophilia to be characteristic of delayed hypersensitivity as seen in experimental skin contact allergy.

It seems reasonable to conclude that the cutaneous inflammatory basophilia found by Rebuck et al.(1963) in patients with ulcerative colitis, and in the present study in patients with other diseases as well, does not represent a new type of hypersensitivity but reflects a delayed hypersensitivity to diphtheria toxoid or atoxic diphtherial proteins.

This work was assisted by grants from Statens almindelige videnskabsfond, P. Carl Petersen's Fond, and Kong Christian den Tiendes Fond.

\section{REFERENCES}

Anthonisen, P., and Riis, P. (1961). A new diagnostic approach to mucosal inflammation in proctocolitis. Lancet, 2, 81-82.

Hu, F., Fosnaugh, R. P., and Livingood, C. S. (1963). Human skin window studies. II. Comparison of cellular response to staphylococcus in controls and in patients with cutaneous bacterial infections. $J$. invest. Derm., 41, 325-334.
Juhlin, L. (1963). Basophil leukocytes in ulcerative colitis. Acta med. scand., 173, 351-359.

Lawrence, H. S., and Pappenheimer, A. M., Jr. (1956). Transfer of delayed hypersensitivity to diphtheria toxin in man.J. exp.Med., 104, 321-336.

McAuley, R. L., and Sommers, S. C. (1961). Mast cells in non-specific ulcerative colitis. Amer. J. dig. Dis., 6, 233-236.

McGovern, V. J., and Archer, G. T. (1957). The pathogenesis of ulcerative colitis. Aust. Ann. Med., 6, 68-74.

Pappenheimer, A. M., Jr., and Lawrence, H. S. (1948). Immunization of adults with diphtheria toxoid. II. An analysis of the pseudoreactions to the Schick test. Amer. J. Hyg., 47, 233-240.

Priest, R. J., Rebuck, J. W., and Havey, G. T. (1960). A new qualitative defect of leukocyte function in ulcerative colitis. Gastroenterology, 38, 715-720.

Rebuck, J. W., Hodson, J. M., Priest, R. J., and Barth, C. L. (1963). Basophilic granulocytes in inflammatory tissues of man. Ann. N.Y. Acad. Sci., 103, 409-426.

—, Petz, A. J., Riddle, J. M., Priest, R. J., and LoGrippo, G. A. (1961). Human leucocytic functions in the tissues. In Biological activity of the leucocyte, (Ciba Foundation Study Group No. 10), edited by G. E. W. Wolstenholme and M. O'Connor. Churchill, London.

Riis, P., and Anthonisen, P. (1964). Eosinophilia in peripheral blood and inflammatory exudate in non-specific proctocolitis. Acta med. scand., 175, 85-89.

Wolf-Jürgensen, P. (1962). Cytological examination of experimental contact allergy using the skin window technique. Acta allerg. $(K b h), 17$, 547-557.

- (1965). Basofile leukocytter i eksperimentelle tuberkulinreaktioner undersøgt med hudvindue-teknik. Nord. Med., 73, 35-37. 